\title{
COMPORTAMENTO E EFEITO DO TITÂNIO DURANTE O PROCESSAMENTO DE UM MINÉRIO DE FERRO
}

\author{
H. D. G. TURRER ${ }^{1}$, K. B. MENEZES, C. R. MAGALHÃES, F. H. P. GONZAGA, J. C. SILVA, J. A. ALMEIDA e C. M. \\ NASCIMENTO
}

${ }^{1}$ Gerência de Controle de Qualidade e Desenvolvimento de Processos do Minas-Rio - Anglo American henrique.turrer@angloamerican.com

Artigo submetido em novembro/2013 e aceito em janeiro/2014

DOI: http://dx.doi.org/10.15628/holos.2014.1761

\section{RESUMO}

O minério de ferro da Serra do Sapo possui características diferentes daqueles oriundos dos mais importantes polos produtores brasileiros, uma vez que foi formado em condições geológicas distintas. Uma característica que o difere é o seu teor de titânio, que alcança valores pouco usuais em algumas regiões do depósito. Este trabalho objetivou verificar o comportamento desse elemento no tratamento de minérios e seu possível efeito nos processos subsequentes da cadeia produtiva do aço. Inicialmente, foi realizada uma revisão bibliográfica sobre o assunto. Em seguida, foram coletadas amostras da região de maior concentração desse elemento para realização de testes em laboratório que simulassem o processo produtivo industrial. Testes de flotação mostraram que a recuperação desse elemento é proporcional a do ferro, indicando associação da hematita com o titânio. As análises em microscópio ótico não foram capazes de identificar minerais portadores de titânio, reforçando a hipótese anterior. Por fim, os teores de dióxido de titânio obtidos no concentrado foram usados para estimar a qualidade esperada do pellet feed. Os resultados mostraram que o teor de dióxido de titânio no concentrado ficou abaixo dos limites exigidos pelo mercado.

PALAVRAS-CHAVE: minério de ferro, flotação, pellet feed, titânio.

\section{TIO2 BEHAVIOUR AND EFFECT IN THE IRON ORE PROCESSING}

\section{ABSTRACT}

Iron ore from Serra do Sapo's deposit has distinct characteristics from the ones exploited in the main Brazilian iron ore production poles since it was formed in different geological conditions. One of these characteristics is the titanium amount, which presents unusual values in some regions of the deposit. This work aimed verifies this element behavior during the mineral processing and its effect in the steelmaking following process. Initially, a bibliographic revision about the subject was performed. Subsequently, ore samples from the region where this element concentration is higher
\end{abstract}

were collected to perform laboratory tests to simulate the industrial process. Flotation tests showed that titanium recovery is proportional to iron recovery, indicating association with hematite. Optical microscopy analysis could not identify titanium minerals, reinforcing the previous hypothesis. Lastly, the titanium dioxide amount in the concentrates was used to estimate the pellet feed quality. The results showed that concentrate titanium dioxide content will be below the usual limits requested by the market.

KEYWORDS: iron ore, flotation, pellet feed, titanium. 


\section{INTRODUÇÃO}

O depósito da Serra do Sapo, localizado no município de Conceição do Mato Dentro, MG, possui, até o momento, aproximadamente 5 bilhões de toneladas de recursos geológicos. A partir desse minério serão produzidos 26,5 milhões de toneladas naturais de pellet feed por ano. 0 processo produtivo contemplará a extração do minério por escavadeiras e caminhões, fragmentação por britadores de mandíbulas e cônicos, prensas de rolos e moinhos de bolas, seguido por deslamagem, flotação, remoagem em moinhos verticais, espessamento, bombeamento por $525 \mathrm{~km}$ de mineroduto e separação sólido-liquido para embarque.

A reserva, com mais de 1 bilhão de toneladas de minério de ferro, formará uma cava que se estenderá por mais de 12 quilômetros na direção norte-sul. Foi observado que em algumas regiões do depósito, onde a operação de lavra foi planejada para ter início, a concentração de titânio é pouco usual comparado à média dos minérios de ferro brasileiros.

Por isso, este trabalhou objetivou verificar o comportamento desse elemento no tratamento do minério e seu possível efeito nos processos subsequentes da cadeia produtiva do aço. Inicialmente foi feita uma revisão bibliográfica em busca de informações que pudessem guiar e suportar as avaliações experimentais. Em seguida, foram realizados testes em escala de laboratório que simulassem o processo produtivo para prever o comportamento do óxido de titânio durante seu futuro processamento industrial.

\section{REVISÃO BIBLIOGRÁFICA}

A apresentação das referências encontradas será feita na ordem inversa do processamento do minério. Iniciará com questões relativas ao titânio na siderurgia, passando pelo tratamento de minério e, por fim, abordará sua forma de ocorrência em alguns depósitos.

A presença de elevadas quantidades de titânio no pellet feed pode ser prejudicial para os processos de redução do óxido de ferro à ferro metálico. Grande parte dos estudos sobre esse assunto é relativa a depósitos de minério de ferro com origem completamente diferente daquele da Serra do Sapo, que possuem titanomagnetita, apresentando um teor de titânio na ordem de $7 \%$ $[1,2]$.

Durante o processo de pelotização, o titânio pode alterar as propriedades da pelota através da difusão na rede da hematita, com geração de trincas ao longo da matriz do aglomerado. Em solução sólida, o titânio também promove uma aceleração da taxa de oxidação da magnetita para hematita [3].

Fornecedores de módulo de redução direta associam o teor de titânio da pelota ao inchamento da mesma. Por isso, sugerem adoção de limites máximos de especificação para evitar a ocorrência de cachos, que diminuem a permeabilidade do leito [4].

No alto forno, o óxido de titânio é reduzido gerando compostos estáveis, chamados de carbonidretos de titânio, ou Ti(N,C), com pontos de fusão muito elevados, que aumentam a viscosidade das fases em que se encontram. Dependendo da temperatura e da quantidade de titânio, esses compostos podem se precipitar na forma sólida. Com isso, o vazamento da escoria e do gusa se tornam muito mais complexos. A concentração mínima de óxido de titânio no gusa, 
para que isso ocorra, é de 0,112 e 0,196\% em 1.400 e $1.500{ }^{\circ} \mathrm{C}$, respectivamente [5]. Contudo, a presença do mesmo apresenta um efeito positivo ao processo, pois promove a formação de uma camada protetora no refratário, elevando sua vida útil. Estudos mostram que adições de 15 até 20 $\mathrm{kg} / \mathrm{t}$ de gusa são necessários para que porções de carbonidretos de titânio sejam mantidos no forno e atuem na proteção dos refratários, uma vez que boa parte do cristais de titânio, precipitados no gusa líquido, são arrastados em direção aos canais de corrida durante o vazamento [6]. Entretanto, essa quantidade pode variar em função da estrutura mineralógica do portador do titânio, pois menores quantidades do mesmo são necessárias quando este se encontra em condições termodinamicamente mais favoráveis [7].

No aço, o titânio eleva a resistência e a dureza, mas diminuiu a ductibilidade. Essas propriedades apresentam uma repentina mudança de comportamento quando o teor de titânio é maior que $0,115 \%$ no gusa, fato atribuído à precipitação do mesmo [8].

Poucos estudos são encontrados sobre o efeito de minerais portadores de titânio no processamento mineral. Em um deles, a concentração de várias amostras provenientes de dois depósitos de minério de ferro na Suécia foi avaliada. Ao todo, 172 amostras foram tratadas, produzindo concentrados com $\mathrm{TiO}_{2}$ variando de 0,002 até $0,399 \%$ com média de $0,059 \%$. Isso permitiu determinar a média dos concentrados oriundos dos dois depósitos como sendo igual a 0,054 e 0,096\%. O autor atribui a presença de titânio a diferentes minerais, já que a relação entre $\mathrm{TiO}_{2}$ e $\mathrm{Al}_{2} \mathrm{O}_{3}$ nas amostras antes do tratamento não era constante. Foi ainda afirmado que os valores de $\mathrm{TiO}_{2}$ das amostras de concentrado estão bem abaixo dos limites máximos exigidos para pelotas de redução direta, que são fornecidas pela empresa exploradora do depósito, com exceção de pequenas partes onde outras técnicas de processamento poderiam ser necessárias [9].

Em se tratando de minérios brasileiros, foi possível obter alguns indicativos do comportamento do óxido de titânio em trabalhos que não tinham esse tópico como um dos objetivos, mas reportaram resultados dos teores de $\mathrm{TiO}_{2}$ nos produtos, possibilitando essa avaliação. Os minerais portadores de titânio tiveram uma maior recuperação no concentrado da etapa de flotação da usina de Brucutu, de propriedade da Vale S.A. Nos resultados apresentados, o teor de titânio na alimentação dessa etapa foi, em dois momentos distintos, de 0,047 e 0,039\%, enquanto no concentrado o teor foi de, respectivamente, 0,131 e 0,122\% [10]. Minério de ferro hematítico, com elevado grau de hidratação, abaixo de $0,15 \mathrm{~mm}$ e contendo elevado teor de ferro, $58,7 \%$, apresentou teor de titânio igual a 0,139\% [11]. Testes de concentração de flotação em bancada com minério anfibolítico também resultaram numa elevada concentração do titânio no concentrado. $\mathrm{O} \mathrm{TiO}_{2}$ dessa amostra subiu de $0,01 \%$ na alimentação da concentração para 0,10\% no concentrado de duas flotações, catiônica reversa e aniônica direta [12]. Testes de concentração magnética com materiais abaixo de $1,0 \mathrm{~mm}$, provenientes de barragem de rejeitos da usina de Córrego do Feijão, no Quadrilátero Ferrífero, resultaram em concentrados com $\mathrm{TiO}_{2}$ de 0,063 e 0,054\%. Nesses testes, a recuperação de titânio no concentrado foi perto de $30 \%$ [13]. Minérios provenientes das minas de Jangada, João Pereira, Fábrica Nova e Serra Serpentina, todas localizadas no Quadrilátero Ferrífero, apresentaram $\mathrm{TiO}_{2}$ de, respectivamente, 0,016, 0,033, 0,023 e $0,036 \%$ no ROM. Contudo, os teores no concentrado não foram reportados [14].

Titânio foi identificado em finas lamelas, de 5 até $0,2 \mu \mathrm{m}$, dispostas em planos cristalinos da estrutura dos óxidos de ferro em concentrados magnéticos brasileiros com teor de $\mathrm{TiO}^{2}$ de 3,16 e 2,51\%. Apesar da difração de raios $X$ não ter detectado nenhum mineral de titânio, a análise em 
microscópio de luz refletida permitiu a identificação de três formas de ocorrência de ilmenita: exsolução com magnetita, cristais em contato com magnetita e cristais individuais [15].

A caracterização de um minério intemperizado, proveniente da mina de Alegria no Quadrilátero ferrífero, mostrou que o titânio encontrado nas amostras de goethita apresentava teores diversos, independente de sua textura e seu grau de cristalinidade, e estaria alojado dentro da estrutura cristalográfica da goethita. Também foi identificada a presença de fases intermediárias da solução sólida hematita-ilmenita [16].

Cinquenta e nove amostras de granulados provenientes de diferentes minas do Quadrilátero foram caracterizadas. O teor médio de $\mathrm{TiO}_{2}$ foi de $0,050 \%$, variando numa ampla faixa, de 0,010 até $0,201 \%$. O autor identificou poros preenchidos por um plasma goethíticohematítico nas amostras mais superficiais com altos valores de alumínio e titânio. Além disso, a proximidade com os cristais de magnetita permitiu concluir que esses plasmas goethíticohematíticos possuíam uma origem supergênica. O teor de $0,201 \%$ de $\mathrm{TiO}_{2}$ em uma amostra foi atribuído a associação com rochas básicas e a alteração supergênica concentrou o elemento no minério mais superficial. Por fim, concluiu-se que o titânio é mais elevado nas tipologias associadas à canga e, secundariamente, nas tipologias porosas, itabiríticas e protominério, relacionado aos eventos genéticos de alteração supergênica [17].

$O$ teor de titânio não é um item contratual de especificação usual para o pellet feed. $O$ pellet feed produzido a partir de minérios do Quadrilátero Ferrífero, e exportado, não apresentam teores de titânio em sua especificação, porém, pelotas produzidas a partir do mesmo minério apresentam um teor máximo de $\mathrm{TiO}_{2}$ que pode variar de 0,038 a 0,045\% [18]. 0 teor máximo de óxido de titânio máximo da especificação de sinter feed produzidos a partir de três diferentes minas australianas varia de 0,08 a $0,09 \%$ [19].

\section{MATERIAL E MÉTODOS}

As amostras de minério de ferro foram obtidas através de sondagem de circulação reversa, com broca de diâmetro igual a 50,5 ou 63,5 mm. Ao todo foram realizados 27 furos, totalizando 1.478 metros. A amostra foi dividida em quarteador rotativo, de forma que um quarto de cada amostra foi usado para compor as amostras de teste. As amostras foram compostas em intervalos de $15 \mathrm{~m}$ aproximadamente.

A moagem do material foi realizada segundo procedimentos internos até obtenção de $90 \%$ passante na malha de $0,150 \mathrm{~mm}$, o que permitiu a determinação do consumo energético da moagem primária. 0 produto da moagem foi deslamado em ciclone piloto com diâmetro de 2", apex e vortex de 4,8 e $13 \mathrm{~mm}$, respectivamente,. Na deslamagem, solução de soda cáustica foi adicionada até que a polpa, com $17 \%$ de sólidos em peso, atingisse o $\mathrm{pH}$ de 11 . A velocidade de bombeamento foi ajustada até a produção de um underflow com $50 \%$ de sólidos em peso. Os testes de flotação foram realizados em cuba de 4,5 I com percentual de sólidos no condicionamento e na flotação ajustados em 60 e 40\%, respectivamente,. Foram utilizadas soluções a $1 \%$ de amina EDA-C da Clariant e amido de milho da Kowaslki. Amido foi gelatinizado com soda cáustica na relação de 5:1 e dosado em somente um nível. O pH da polpa foi ajustado para 10,5 com soda cáustica. $O$ amido foi condicionado por 5 minutos antes da adição da amina, que foi condicionada por 1 minuto. A agitação foi controlada em 1.300 e 1.500 rpm, no 
condicionamento e na flotação, respectivamente. A coleta do material flotado aconteceu por 6 minutos após inicio da aeração. Os resultados foram reconciliados com programa de balanço de massas Bilco.

Ensaios granulométricos à úmido foram realizados em vibrador suspenso com peneiras da série Tyler. Os ensaios para determinação da composição química das amostras foram realizados por fluorescência de raios $X$ de pó prensado ou, em alguns casos, de pastilha fundida com equipamento Axios da Panalytical. A perda ao fogo foi determinada por calcinação em mufla, a $1.100{ }^{\circ} \mathrm{C}$. Análise mineralógica foi conduzida em microscópio ótico Olympus BX51TRF com magnificação máxima de 200 vezes.

\section{RESULTADOS E DISCUSSÕES}

As amostras foram classificadas tipologicamente segundo os teores de ferro, fósforo e alumina, além da descrição visual do testemunho. Grande parte das amostras foi classificada como itabirito friável (IF), com pequena participação de cangas mineralizadas (CGM), localizadas nas porções superficiais dos furos, seguido de quartzito ferruginoso (QF), itabirito friável com alta alumina (IFX) e hematita (HM).

As amostras de IFX e CGM apresentaram teores de óxido de titânio maior que as demais, com exceção de algumas poucas classificadas como IF, Figura 1a. Além disso, foi observada uma nítida correlação entre o teor de alumina e de óxido de titânio nas amostras de minério, Figura $1 \mathrm{~b}$. Suspeita-se que o titânio esteja presente em minerais associados a intrusões do manto de rochas meta-diabásicas ricas em alumina e titânio durante os eventos de formação do depósito.
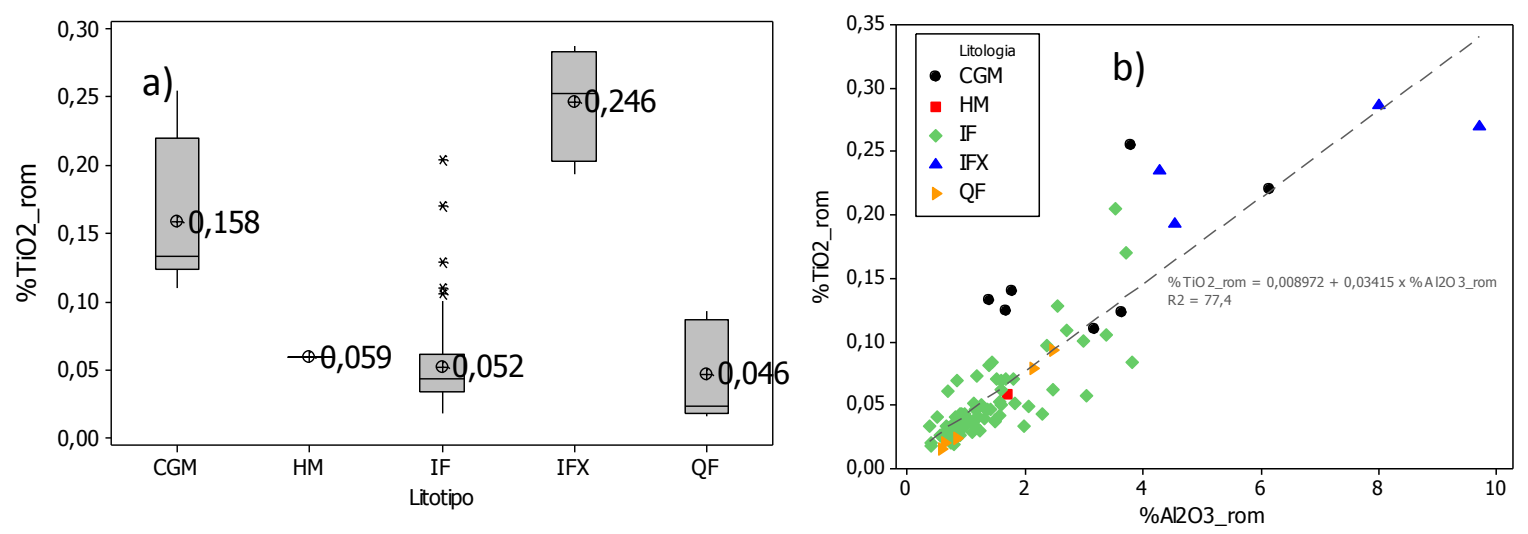

Figura 1 - Teores de óxido de titânio das amostras avaliadas, classificadas em função da litologia (a) e em função do teor de alumínio das mesmas (b).

Grande parte do titânio alimentado foi recuperado no concentrado, Figura 2a. Somente a canga apresentou uma maior recuperação desse elemento nas lamas. Contudo, essa tipologia foi a que apresentou uma maior perda de massa nas lamas também.

Foi comprovado, através de análise de variância e pela correlação da Figura 2b, que o teor de titânio no minério tem um grande efeito no seu teor no concentrado. 
Não foram observadas, Figura 3, altas correlações entre o teor de óxido de titânio no minério e seu desempenho na flotação, indicando que esse fator não tem forte efeito no desempenho dessa etapa.
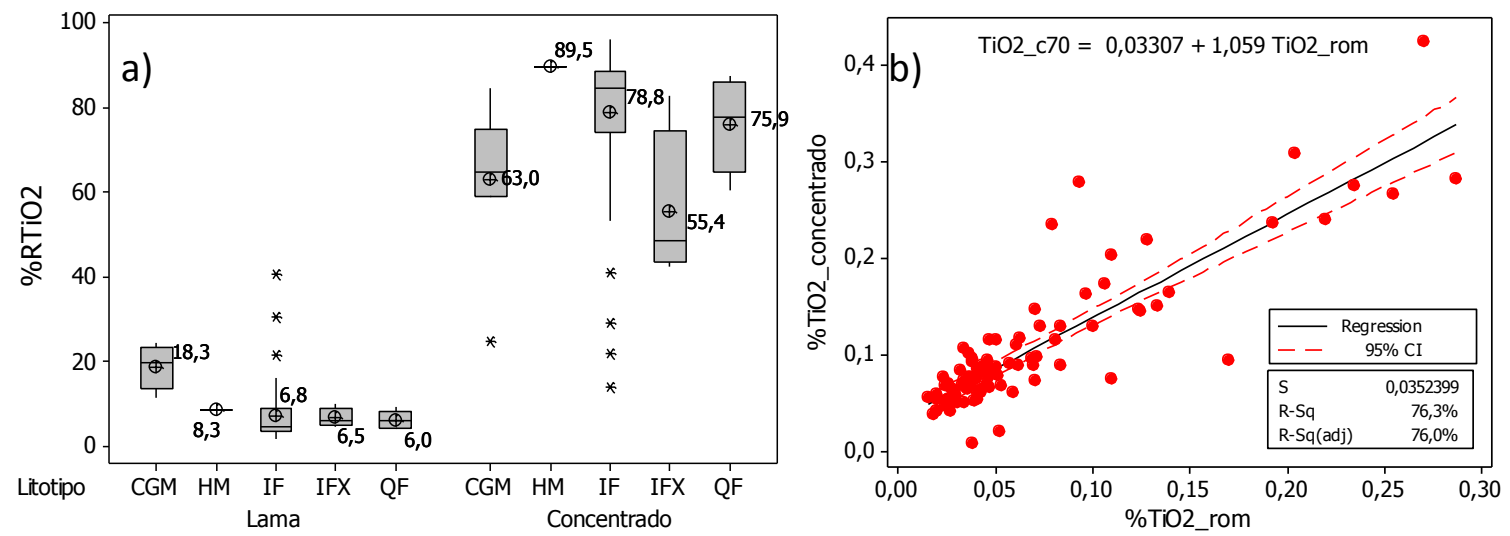

Figura 2 - Comportamento do titânio durante o processamento do minério: recuperações em função da tipologia (a) e correlação de teor no minério e no concentrado (b).
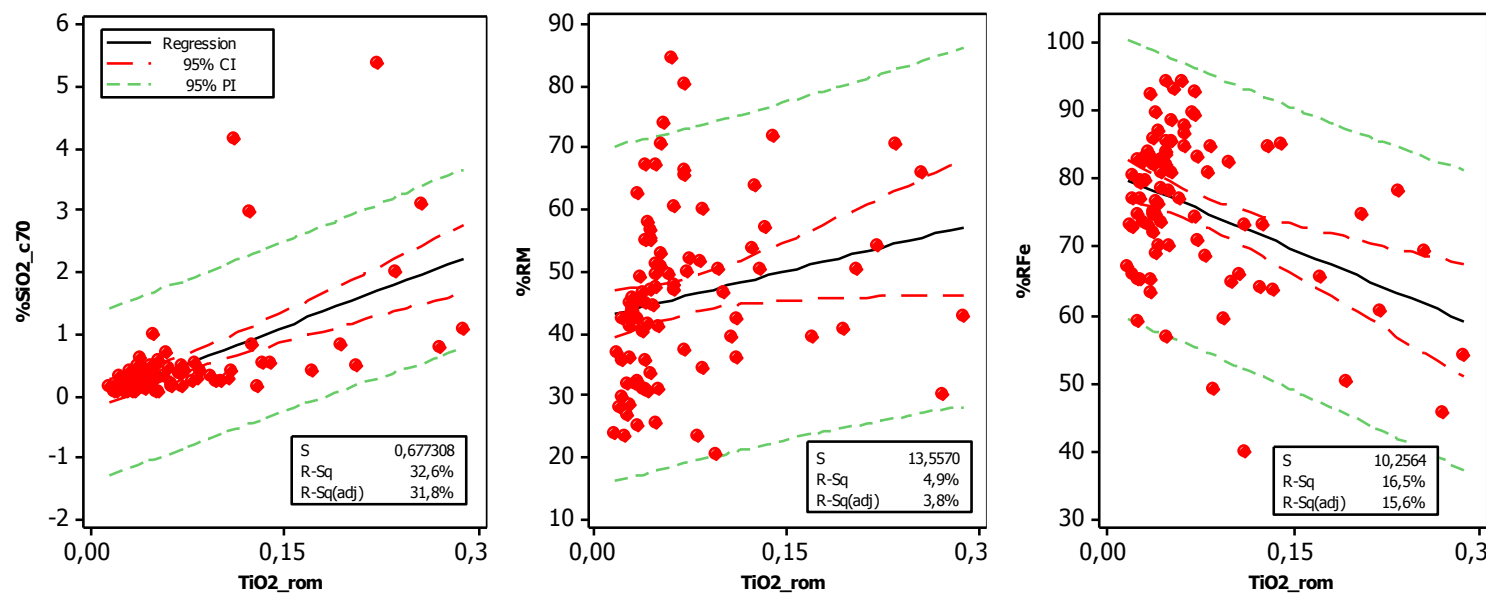

Figura 3 - Efeito do teor de titânio no ROM no desempenho (sílica no concentrado, recuperação mássica e metalúrgica) no processamento do minério.

Algumas das amostras testadas sequer seriam consideradas minérios, por exibirem teores de alumina elevados, maior que $8 \%$, e baixo teor de ferro, menor que $25 \%$. Por isso, as mesmas não seriam direcionadas para usina de tratamento, mesmo em pequenas proporções.

Ainda assim, a média das amostras restantes não representa a média de toda a região de onde elas foram extraídas. Para a determinação desse valor, as massas representativas de cada amostra no depósito deveriam ser consideradas para determinação da média ponderada, como feito por Abongwa [9]. Uma vez que ainda não é possível determinar as massas representativas, é aconselhável que somente as amostras de IF, que serão alimentadas em grandes proporções na usina, sejam consideradas para projeção da qualidade média do concentrado. As amostras de IF apresentaram qualidade média do ROM e do concentrado muito próxima do planejado. Contudo, observa-se que algumas poucas amostras, $25 \%$ do total, estão com valores mais elevados. Em casos 
como esse, em que a variabilidade das amostras é elevada, valores extremos podem influenciar muito a média. Nesses casos, a mediana se torna uma medida descritiva mais adequada para as amostras [20]. Uma forma de quantificar a variabilidade é através do coeficiente de variação, razão entre o desvio padrão e média. Quando o mesmo for superior a 20\%, é aconselhável que a mediana seja usada para representar a população. As amostras apresentaram um coeficiente de variação de $57 \%$ para o $\mathrm{TiO}_{2}$ no concentrado e uma mediana de $0,077 \%$.

Por fim, foram realizadas análises mineralógicas em busca da identificação do mineral portador de titânio em duas amostras, uma de IF e outra de IFX, que apresentaram elevado teor de titânio no ROM e no concentrado com morfologia distinta, Tabela I.

Tabela I - Composição química das amostras analisadas em microscópio

\begin{tabular}{c|c|c|c|c|c|c|c|c|c|c}
\hline \multirow{2}{*}{ Tipologia } & \multicolumn{4}{|c|}{ Composição do minério (\%) } & \multicolumn{5}{c}{ Composição do concentrado (\%) } \\
\cline { 2 - 11 } & $\mathrm{Fe}$ & $\mathrm{Al}_{2} \mathrm{O}_{3}$ & $\mathrm{SiO}_{2}$ & $\mathrm{P}$ & $\mathrm{TiO}_{2}$ & $\mathrm{Fe}$ & $\mathrm{Al}_{2} \mathrm{O}_{3}$ & $\mathrm{SiO}_{2}$ & $\mathrm{P}$ & $\mathrm{TiO}_{2}$ \\
\hline IFX & 53,5 & 8,01 & 14,2 & 0,111 & 0,287 & 67,2 & 1,07 & 0,7 & 0,044 & 0,282 \\
\hline IF & 45,3 & 3,52 & 29,3 & 0,067 & 0,204 & 67,2 & 0,49 & 2,4 & 0,054 & 0,308 \\
\hline
\end{tabular}

A análise das imagens geradas por microscópio eletrônico não permitiu a identificação de nenhum mineral portador de titânio, como titanita ou ilmenita, indicando que o titânio poderia estar presente na estrutura cristalina do mineral de ferro. Essa hipótese só poderá ser comprovada com a utilização de outras técnicas de caracterização, como microscopia eletrônica de varredura aliada a espectroscopia de energia dispersiva, como realizado por Rocha [16]. Contudo, optou-se por não prosseguir com uma caracterização mais detalhada, uma vez que o objetivo principal do estudo não era a caracterização da fonte de titânio e o mesmo não apresentou efeito significativo no desempenho do processamento mineral e nem na qualidade final do concentrado.

Na Figura 4, um exemplo das imagens obtidas, é possível identificar uma série de óxidos de ferro e quartzo, mas nenhum mineral de titânio.

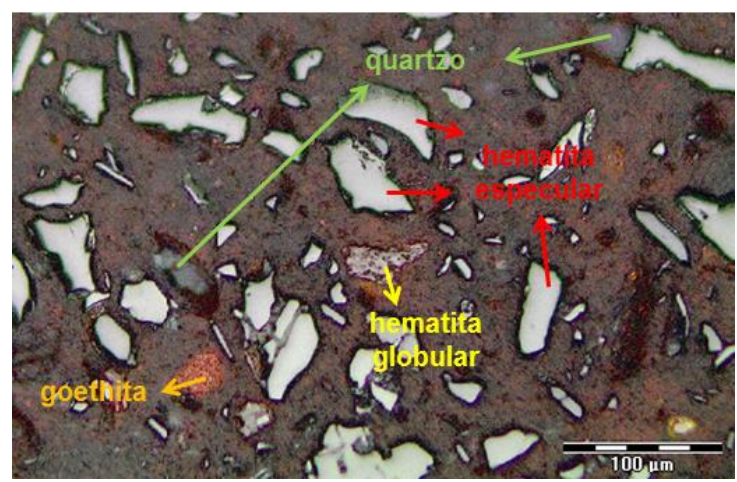

Figura 4 - Imagem obtida em microscópio de concentrado (IF) com elevado teor de titânio.

\section{CONCLUSÕES}

O teor de dióxido de titânio no ROM é diretamente proporcional ao teor de alumina. A média de $\mathrm{TiO}_{2}$ das amostras analisadas é igual a 0,069\%. O titânio é recuperado preferencialmente 
no concentrado, ou, em outras palavras, $76 \%$ do $\mathrm{TiO}_{2}$ alimentado foi, em média, recuperado no concentrado. $O$ teor de titânio no ROM não afetou o desempenho do processamento mineral. Foi possível estimar o teor médio de $\mathrm{TiO}_{2}$ no concentrado do minério extraído da região como sendo igual a $0,077 \%$. Não foram identificados minerais portadores de titânio.

\section{AGRADECIMENTOS}

Os autores gostariam de registrar o agradecimento aos colegas de Anglo American Aguinaldo Pereira Sander, Junio Simões Pereira, Marcelo de Castro, Naldio da Silva Vertelo, Rodrigo Faustino Gomes pela dedicação, esforço e comprometimento na realização dos testes e análises.

\section{REFERÊNCIAS BIBLIOGRÁFICAS}

1. PARK, P.; OSTROVSKI, O. Reduction of Titania-Ferrous Ore by Carbon Monoxide. ISIJ International, v. 43, n.9, p.1316-1325, 2003.

2. PARK, P.; OSTROVSKI, O. Reduction of Titania-Ferrous Ore by Hydrogen. ISIJ International, v.44, n.6, p.999-1005, 2004.

3. BUDZIK, R. The balance of titanium and vanadium in the blast furnace with the use of sinter containing a titanium-vanadium-magnetite concentrate. Metalurgia, v. 46, n. 2, p.145-147, 2007 apud Domingues, A. L. A.; Scudeller, L. A. M.; Pereira, A. S. G. Caracterização mineralógica de concentrado magnetítico com presença de titânio e bário. In: Anais do 41으 Seminário de Redução de Minério de Ferro e Matérias-primas e 12은 Seminário Brasileiro de Minério de Ferro. p.928-939, 2011.

4. HYL. Disponível em <http://www.energiron.com/Tour/HYL\%20DR-Minimill\%20QTVR\%20tour /start.html> Acessado em: 08/01/2013.

5. WU, J.Y.; HO, C.K. Investigation of Titanium Compound Formation in the Blast Furnace Hearth. China Steel Technical Report, n.22, p.23-28, 2009.

6. PEREIRA, J.L.G.; CAMPANHOLO, B.A.; SILVA, M.B.L.; SILVA, A.L.; SILVA, R.B.L. Titanium Goiás Decades of experience in marketing of ilmenite for blast furnaces in Brazil. In: Proceedings of 6th International Congress on the Science and Technology of Ironmaking, 42nd International Meeting on Ironmaking and 13th International Symposium on Iron Ore, p.642-657, 2012.

7. MANSO, G.A.C.; SANTOS, G.S.; OLIVEIRA, M.A.G.; FERNANDES, M.V.; AMIRZADEH-ASL, D.; FÜNDERS, D. Preservação do cadinho do alto forno 3 da Usiminas com injeção de titânio sintético. In: Anais do 410 Seminário de Redução de Minério de Ferro e Matérias-primas e 12으 Seminário Brasileiro de Minério de Ferro, p.533-543, 2011.

8. OKANO, A.N. Influência do titânio na microestrutura e propriedades mecânicas de um aço CMn microligado com 0,08 a $0,16 \%$ de titânio produzindo em tiras laminadas a quente. Dissertação de Mestrado em Engenharia Metalúrgica e de Minas da Escola de Engenharia da UFMG, 80p., 1985.

9. ABONGWA, P.W. Mineral texture and composition of magnetite in the sahavaara IOCG deposit, Pajala área - A mineral processing approach. Master's thesis presented to the Departmant of Chemincal Engineering and Geosciences of Lulea University of Technology, 
126p., 2009.

10. SALES, C. G.;LIPPER, G.;PAULA, N. N.;PEREIRA, J. M.;ROBERTO, J. B.; FONSECA, A.;MACHADO, B. H. Otimização do circuito de flotação reversa de minério de ferro da usina de concentração de Brucutu. In: Anais do 40ㅇ Seminário de Redução de Minério de Ferro e Matérias-primas e 11은 Seminário Brasileiro de Minério de Ferro, p.111-118, 2010.

11. TOTOU, A.R. Efeito da dispersão em polpas de minérios hematíticos com elevado grau de hidratação. In: Anais do 40 Seminário de Redução de Minério de Ferro e Matérias-primas e 11은 Seminário Brasileiro de Minério de Ferro, p.186-194, 2010.

12. SANTOS; D.F.; VIANA, P.R.M.; ARAUJO, A.C.; SANTOS, J.G.; TEIXEIRA, H.G. Flotação de minérios de ferro anfibolíticos - uma revisão. In: Anais do 39o Seminário de Redução de Minério de Ferro e Matérias-primas e 10ㅇ Seminário Brasileiro de Minério de Ferro, 10p., 2009.

13. ZAPPAROLI, A.C.; GUIMARÃES, N.C.; PIRET, W.; CALIXTO, M.; PAULA, C.J.; BENTO, P.; SIMÕES, H.G. Reaproveitamento de depósitos de rejeitos de minério de ferro nos sistemas sul e sudeste da vale: exemplo da barragem de córrego do feijão. Anais do 39올eminário de Redução de Minério de Ferro e Matérias-primas e 10 Seminário Brasileiro de Minério de Ferro, 12p., 2009.

14. LIMA, R.M.F.; LOPES, G.M.; GONTIJO, C.F. Flotação inversa de minérios de ferro de baixos teores do quadrilátero ferrífero - MG. In: Anais do 40 Seminário de Redução de Minério de Ferro e Matérias-primas e 11으 Seminário Brasileiro de Minério de Ferro, p.155-164, 2010.

15. DOMINGUES, A.L.A.; SCUDELLER, L.A.M.; PEREIRA, A.S.G. Caracterização mineralógica de concentrado magnetítico com presença de titânio e bário. In: Anais do 41으 Seminário de Redução de Minério de Ferro e Matérias-primas e 12은 Seminário Brasileiro de Minério de Ferro, p.928-939, 2011.

16. ROCHA, J.M.P. Caracterização Mineralógica de minérios goethíticos-limoníticos da mina de Alegria, MG. Dissertação de Mestrado em Engenharia Metalúrgica e de Minas da Escola de Engenharia da UFMG, 263p., 1997.

17. FERNANDES, E.Z. Caracterização física, química, mineralógica e metalúrgica dos produtos granulados de minério de ferro. Tese de Doutorado em Engenharia Metalúrgica e de Minas da Escola de Engenharia da UFMG, 299p., 2008.

18. SAMARCO. Disponível em <http://www.samarco.com/uploads/xgccbf.pdf> Acessado em: 08/01/2013.

19. BHP. Disponível em <http://www.google.com.br/url?sa=t\&rct=j\&q=bhp\%20billiton\%20pro duct\%20specifications_march\%202012\&source=web\&cd=1\&cad=rja\&ved=0CDQQFjAA\&url= http\%3A\%2F\%2Fwww.bhpbilliton.com\%2Fhome\%2Fbusinesses\%2FDocuments\%2FBHP\%252 0Billiiton\%2520Product\%2520Specifications\%2520June\%25202011.pdf\&ei=k1rsULLUHtSY1A WjloGgDQ\&usg=AFQjCNFcS3-WmfSYIrxwj07hxY_ur72RkA\&bvm=bv.1357316858,d.d2k> Acessado em: 08/01/2013.

20. STEVENSON, W.J. Estatística aplicada à administração. Harper \& Row do Brasil, p.23, 1981. 